\title{
Predicting Coastal Flooding and Wetland Loss
}

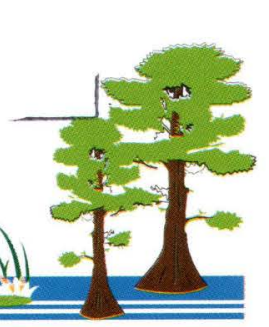

$\mathbf{T}_{\mathrm{h}}$

he southeastern coastal region encompasses vast areas of wetland habitat important to wildlife and other economically valuable natural resources. Located on the interface between sea and land, these wetland habitats are affected by both sealevel rise and hurricanes, and possibly by hydroperiod associated with regional climatic shifts. Increased sea level is expected to accompany global warming because of higher sea temperatures and ice melt. To help determine the effects of sealevel rise on these wetlands, USGS scientists created computer models of coastal flooding and wetland loss.

These models augment field and laboratory studies by integrating our knowledge and understanding of natural and physical systems into a single framework. We examined the impacts of sea-level rise scenarios on wetland habitats of federal parks and refuges along the Gulf of Mexico. A geographic information system (GIS)based simulation model was developed to predict ecosystem response to changing environmental conditions for wetland areas of the Big Bend region in northwest Florida. The model describes plant community sensitivity to hydrologic conditions linked with a GIS database of site characteristics, including habitat type, elevation, soils, and land use.

\section{St. Marks Refuge}

This regional model application includes the aquatic and terrestrial habitats of St. Marks National Wildlife Refuge (Fig. 1), a 65,000-acre refuge $20 \mathrm{mi}$ south of Tallahassee covering parts of Wakulla, Jefferson, and Taylor counties. The refuge borders Apalachee Bay on the south, Ochlockonee Bay on the west, and Aucilla River on the east. The landscape is characterized by a relatively low elevational gradient intersected by several rivers and a number of freshwater springs and intertidal creeks. Upland pine sandhills drain into wet pine flatwoods and hardwood swamps within the freshwater zone and into tidal salt marsh and mudflats at bay's edge. Seagrass beds are

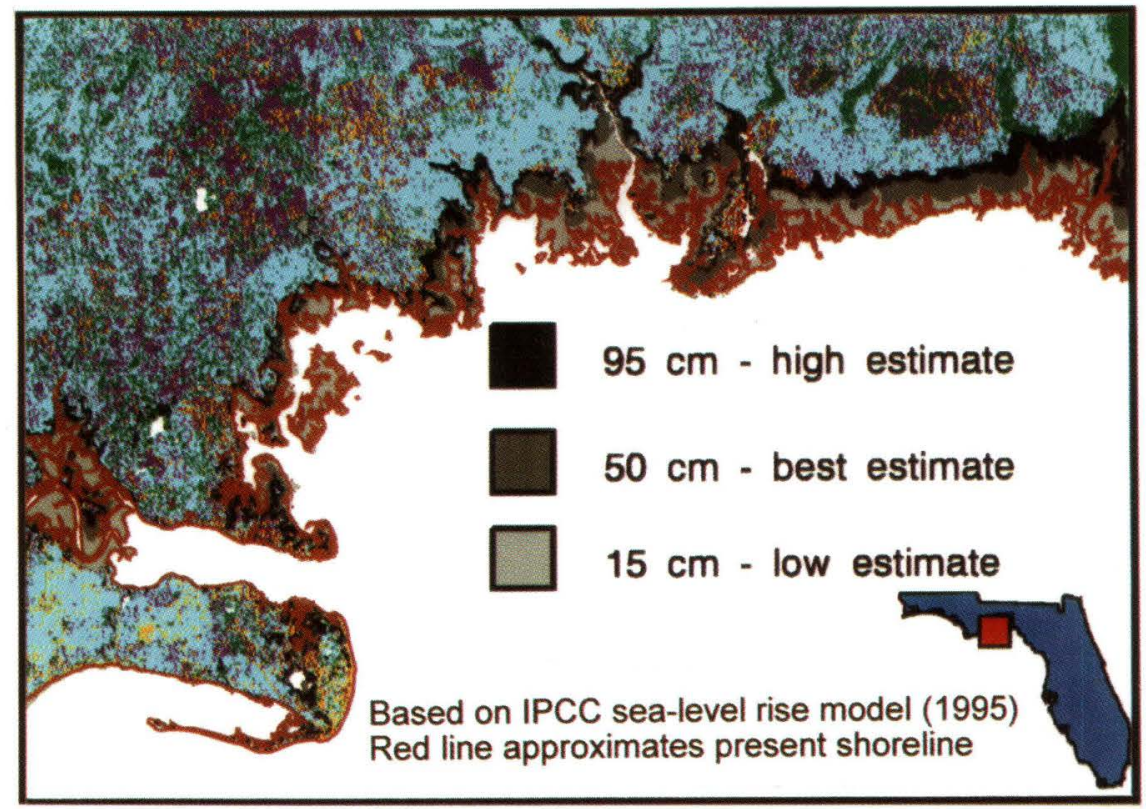

Fig. 1. Predicted shoreline changes by 2100 showing coastal inundation of the St. Marks NWR area, Florida, for low, mid (best), and high projections of sea-level rise, adopted by the Intergovernmental Panel on Climate Change.

abundant throughout Apalachee Bay, a shallow, low energy system open to the Gulf of Mexico. Elevations of these major habitat types range from below sea level for seagrass; $0-2 \mathrm{ft}$ above mean sea level for salt and fresh marsh (Fig. 2); 1-4 ft above mean sea level for lowland pine, palm, hardwood hammocks; $4-6 \mathrm{ft}$ above mean sea level for bottomland hardwood and pine flatwoods; and 6-40 ft above mean sea level for pine sandhill and oak associations in the higher elevations.

\section{Field Surveys}

Land elevation and tidal inundation are key factors controlling habitat type and distribution in this coastal environment. We conducted plot and transect surveys to derive a conceptual model of community types and succession under different environmental conditions and disturbance regimes. Vegetation descriptions and elevation data were collected across the forest-marsh transitional zone.

The significance of our field study was that we could plot elevation 


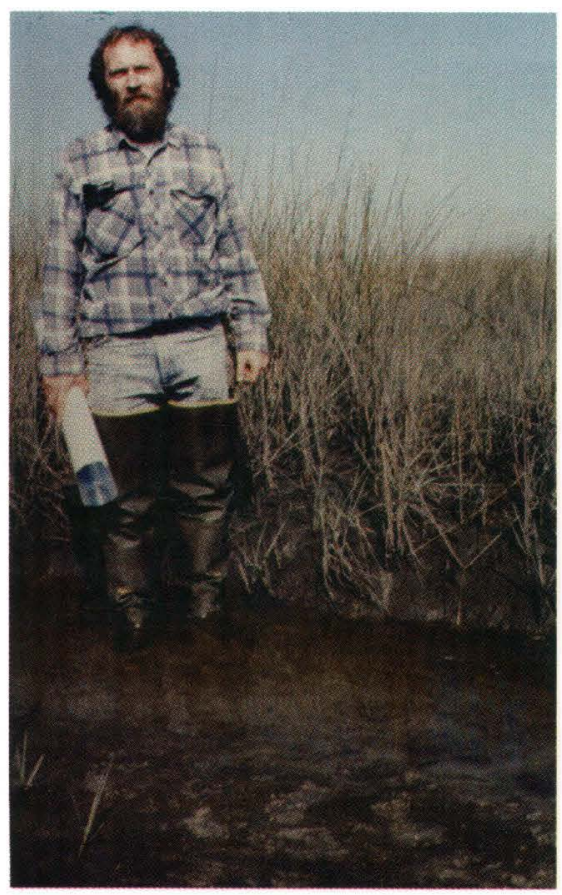

Fig. 2. USGS researcher showing the height of marsh surface above surrounding water.

contours within the needlerush marsh landscape by identifying the vegetation on aerial photography and even satellite imagery. Sand flats occupied by turtleweed and glasswort are highly visible on remote imagery and occur at the same elevation as mean high water (about 36-40 $\mathrm{cm}$ above mean sea level) from predicted tide tables for the area. Also highly visible is the distinct marsh-forest boundary occurring near the elevation of the highest predicted tides from the same tide tables $(60-70 \mathrm{~cm}$ above mean sea level). These vegetation boundaries provided proxy elevation contours that were used to estimate the slope and produce an elevation gradient model of the study area. The probability of species and plant communities tolerating coastal flooding was also determined from these field surveys and used to predict changes in habitats.

\section{Model Development}

A digital elevation model of the study area was constructed to track the process and pattern of coastal inundation over space and time for projections of sea-level rise. Model simulations were generated to predict a likelihood index of habitat change and conversion under flooded conditions for different scenarios of sea-level rise.

Sea-level rise was simulated based on a series of case projections (low, mid, and high) for the years 2000 to 2100 adopted by the Intergovernmental Panel on Climate Change (1995; Fig. 3). At these levels, major portions of the coastal zone in this region would be permanently inundated over the next century, bringing about a migration upslope of marsh habitat and a loss in the total area and proportion of forest habitats.

\section{Results}

Model results show that there is a large landbase that will be converted from marsh to open water and forest to marsh. However, due to the slope of the landform, coastal marsh is predicted to increase slightly in land cover as it migrates upslope and replaces existing forest habitat. A significant portion of coastal pinelands that stand at or below the 1-m contour would be lost given a projected sealevel increase of $0.95 \mathrm{~m}$ (high) over the next century. The model predicts an effective migration of emergent marsh into forested zones, but it also indicates an overall net loss of terrestrial habitat to an open water environment.

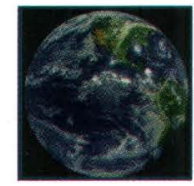

\section{For more information, contact}

Thomas W. Doyle

U.S. Geological Survey

National Wetlands Research Center 700 Cajundome Blvd.

Lafayette, LA 70506

318-266-8647

tom_doyle@usgs.gov

http://www.nwrc.gov

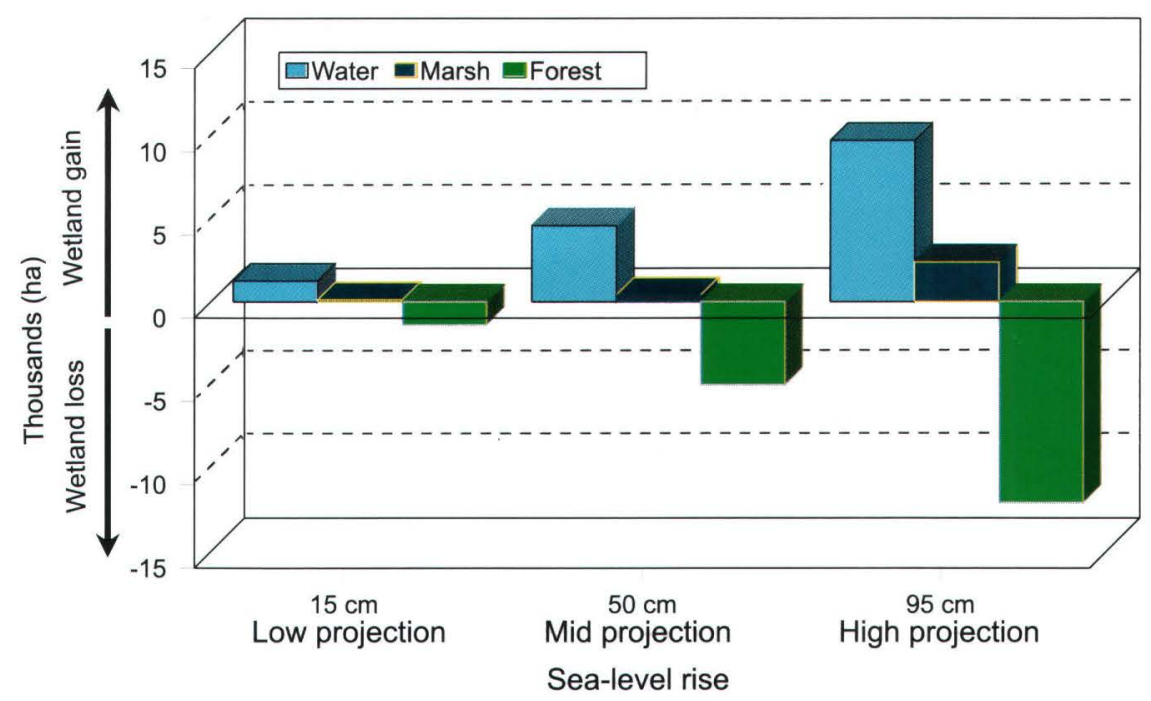

Fig. 3. Predicted changes of net loss and/or gain of open water, emergent marsh, and forest for low, mid, and high sea-level rise by the year 2100. 